[Agr. Biol. Chem., Vol. 35, No. 6, p. 899 904, 1971]

\title{
Gluconate Metabolism by a Thiamine-requiring Species of Corynebacterium
}

\author{
Part IV. Accumulation of D-Ribulose \\ By Mutsuo Shimamura, Juichi Yoshitake and Tomio ImaI \\ Central Research Laboratory, Godo Shusei Co., Ltd. \\ Matsudo, Chiba, Japan \\ Received December 3, 1970
}

\begin{abstract}
A thiamine-requiring strain of Corynebacterium was found to accumulate a ketopentose extracellularly from gluconate. The ketopentose was isolated from the culture medium and identified as D-ribulose. The accumulation of D-ribulose was significantly infuenced by the concentration of thiamine in the medium. The maximum yield of D-ribulose was obtained at a thiamine concentration of $10 \mu \mathrm{g}$ per liter, whereas good growth was favored at thiamine concentrations greater than $50 \mu \mathrm{g}$ per liter. The accumulation of D-ribulose reached the concentration of $9.5 \mathrm{mg}$ per $\mathrm{ml}$ after cessation of cell growth in shake culture at $30^{\circ} \mathrm{C}$ in a medium containing $6 \%$ potassium gluconate as a carbon source.
\end{abstract}

In our previous papers, it was shown that a thiamine-requiring bacterium, Corynebacterium sp. No. 208, was capable of accumulating pyruvic acid extracellularly when the organism was grown in a thiamine-deficient medium containing gluconate as a sole source of carbon. ${ }^{1,2}$ In addition, the cause of the accumulation of pyruvic acid by the thiamine-deficient cells was confirmed to be due to the decrease in the activity of pyruvate dehydrogenase. ${ }^{3 !}$

During the further studies on gluconate metabolism under the condition of thiamine deficiency, this organism was also found to accumulate D-ribulose in the culture medium.

The production of D-ribulose from glucose by microorganisms has been reported with

This study was presented at the Annual Meeting of the Agricultural Chemical Society of Japan, March $31,1967$.

1) M. Shimamura and J. Yoshitake, Nippon Nogeim kagaku Kaishi, 44, 189 (1970).

2) M. Shimamura and J. Yoshitake, ibid,, 44, 195 (1970).

3) M. Shimamura and J. Yoshitake, ibid., 44, 283 (1970). some bacteria such as Brevibacterium fuscum," Agrobacterium tumefaciens, ${ }^{51}$ Corynebacterium sp. ${ }^{61}$ and Bacillus sp." In these organisms, however, the reason of the accumulation of $\mathrm{D}$ ribulose is not clear.

With Corynebacterium sp. No. 208 used in the present study, the accumulation of D-ribulose was predominantly influenced by the concentration of thiamine in the culture medium. Accordingly, it was considered interesting to investigate a role of thiamine in the accumulation of D-ribulose by this organism.

The present paper deals with the identification of the ketopentose accumulated in the culture medium and the investigation of factors influencing the accumulation of D-ribulose

4) N. Saito and S. Sugiyama, Agr. Biol, Chem., 28, 48 (1964).

5) T. Suzuki and R. M. Hochster, Biochem. Biophys. Res. Commun., 19, 637 (1965).

6) M. Misawa, T. Nara and S. Kinoshita, Agr. Biol. Chem., 31, 611 (1967).

7) K. Sasajima and M. Yoneda, Abstracts of Papers, The Annual Meeting of the Agricultural Chemical Society of Japan, Tokyo, 1969, p. 191. 
by this organism.

\section{MATERIALS AND METHODS}

Organism. Corynebacterium sp. No. 208, which was isolated from soil by the authors, was used throughout the experiments. This organism strictly requires thiamine for growth and is capable of rapid growth on gluconate as a sole source of carbon as previously reported. ${ }^{11}$

Cultural conditions. The organism was grown on a bouillon agar slant for $24 \mathrm{hr}$ at $30^{\circ} \mathrm{C}$ and a loopful of cells was inoculated to each flask containing the production medium. The basal production medium consists of potassium gluconate, $6.0 \% ;\left(\mathrm{NH}_{4}\right)_{2} \mathrm{SO}_{4}, 0.4 \%$; $\mathrm{KH}_{2} \mathrm{PO}_{4}, 0.1 \% ; \mathrm{MgSO}_{4} \cdot 7 \mathrm{H}_{2} \mathrm{O}, 0.05 \%$; and thiamine hydrochloride, $10 \mu \mathrm{g}$ per liter; at $\mathrm{pH}$ 7.0. Cultivation was carried out at $30^{\circ} \mathrm{C}$ for 96 to $120 \mathrm{hr}$ on a reciprocal shaker operating at $220 \mathrm{rpm}$.

Paper chromatography. $n$-Butanol-pyridine-water (6: $4: 3, v / v), n$-propanol-ethyl acetate-water $(7: 1: 2, v / v)$, and water-saturated phenol were employed as solvents for the separation of sugars by ascending paper chromatography. Water-saturated $n$-butanol was used for the chromatographic analysis of 0 -nitro-phenylhydrazone of ketopentoses. Sugars were detected on papers with aniline hydrogen phthalate, $p$-anisidine, orcinoltrichloroacetic acid (TCA), resorcinol hydrochloride, and anthrone hydrochloride reagents. Toyo Roshi No. 50 paper was used in all experiments.

Ion exchange chromatography. Ion exchange chromatography with an anion exchange resin Dowex 1-X2 was performed for the separation of ketoses. This anion exchange resin was converted to the borate form and washed with $0.01 \mathrm{M}$ potassium tetraborate before applying the test material to the column.

Analytical methods. Ketopentoses were identified by the color reactions given by orcinol hydrochloride ${ }^{81}$ and cysteine-carbazole-sulfuric acid. ${ }^{9 /}$ D-Ribulose was determined in the cysteine-carbazole reaction. ${ }^{91}$ For the determination of D-ribulose in the culture medium, quantitative paper chromatography with $n$-butanol-

8) R. Sato, M. Ebata and T. Kojima, J. Biochem. (Tokyo), 41, 307 (1954).

9) Z. Dische and E. Borenfreund, J. Biol. Chem., 192, $583(1951)$. pyridine-water as a solvent was accomplished before the colorimetric determination of the ketopentose. The cell growth was determined as dry weight of cells and expressed in $\mathrm{mg}$ per $\mathrm{ml}$ of culture medium.

Materials. D-Ribulose o-nitro-phenylhydrazone is of commercial origin (California Corporation Biochemical Research). Free D-ribulose was prepared from the o-nitro-phenylhydrazone. ${ }^{10)}$ Xylulose was prepared by isomerization of xylose in boiling pyridine. 11

\section{RESULTS}

Isolation and identification of D-ribulose accumulated in the culture medium

To obtain the sugar which was submitted to the identification, Corynebacterium sp. No. 208 was grown in the basal production medium shown in Materials and Methods.

After $96 \mathrm{hr}$, the filtrate of the cultured broth was applied to paper chromatography. A single spot was found by spraying with aniline hydrogen phthalate, orcinol-TCA, anthrone hydrochloride, resorcinol hydrochloride, or $p$ anisidine. The $R f$ values of the product in

Table I. Paper Chromatography of Sugars

\begin{tabular}{lcc}
\multicolumn{1}{c}{ Sugars } & \multicolumn{2}{c}{$R f$ values } \\
& Solvent 1 & Solvent 2 \\
\hline Glucose & 0.40 & 0.35 \\
Fructose & 0.42 & 0.38 \\
Arabinose & 0.41 & 0.38 \\
Ribose & 0.52 & 0.45 \\
Xylose & 0.48 & 0.43 \\
Ribulose & 0.58 & 0.50 \\
Xylulose & 0.58 & 0.50 \\
Sedoheptulose & 0.38 & 0.37 \\
Product & 0.57 & 0.49
\end{tabular}

Solvent 1: $n$-Butanol-pyridine-water $(6: 4: 3, \mathrm{v} / \mathrm{v})$

Solvent 2: $n$-Propanol-ethyl acetate-water $(7: 1: 2$, $v / v)$

10) T. Reichstein and W. Bosshaad, Helv. Chim. Acta, 17, 753 (1934).

11) O. T. Schmidt and R. Treiber, Ber., 66, 1765 (1933). 
two different solvent systems closely agreed with those of authentic ribulose as shown in Table I. Homogeneity of the product was also confirmed by additional two dimensional paper chromatography with $n$-butanol-pyridinewater and water-saturated phenol as solvents. The spot of the product gave orange color by spraying with orcinol-TCA reagent and showed fluorescence under ultraviolet irradiation. Since these reactions on paper are characteristic for ribulose, ${ }^{12}$ the product is presumed to be ribulose. No sugar phosphates were detected paper-chromatographically.

For the identification of the ketopentose, the isolation of the product from the cultured broth was carried out as follows. After centrifugation of the cultured broth, the supernatant was deproteinized by the addition of $25 \%$ zinc sulfate, neutralized to $\mathrm{pH} 7.8$ with barium hydroxide, and then filtered. The filtrate was passed through a column of Amberlite IR-120 in the acid form and the effluent was concentrated in vacuo at $30^{\circ} \mathrm{C}$. The precipitate occured was removed by centrifugation. The supernatant was acidified with sulfuric acid and extracted with ether for $98 \mathrm{hr}$ to remove pyruvic acid. The ether-insoluble fraction was neutralized to $\mathrm{pH} 7.8$ with barium hydroxide and then centrifuged. Subsequently, column chromatography with Dowex 1-X2 in the borate form was performed for the separation of the ketopentose. After the supernatant was applied to the column, elution was begun with $0.04 \mathrm{M}$ potassium tetraborate. The cysteine-carbazole positive fraction was converted to the free acid by passage through a column of Amberlite IR-120 in the acid form, and the effluent was evaporated to dryness in vacuo at $30^{\circ} \mathrm{C}$. Methanol was added to the residue and boric acid was removed as methyl borate under reduced pressure. The residue was dissolved in water, filtered, and then the filtrate was evaporated to a sirup in vacuo at $30^{\circ} \mathrm{C}$.

12) P. K. Stumpf and B. L. Horecker, J. Biol. Chem., 218, 753 (1956).

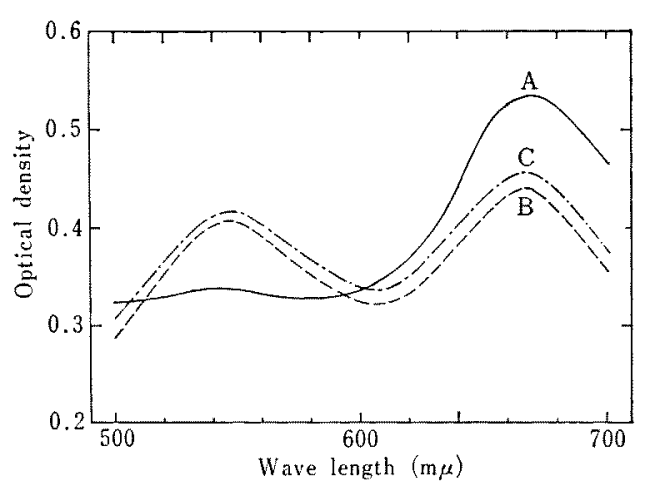

FIG. 1. Absorption Spectra of Ketopentoses in the Orcinol Reaction.

A: Authentic xylulose

B: Authentic ribulose

C: Product

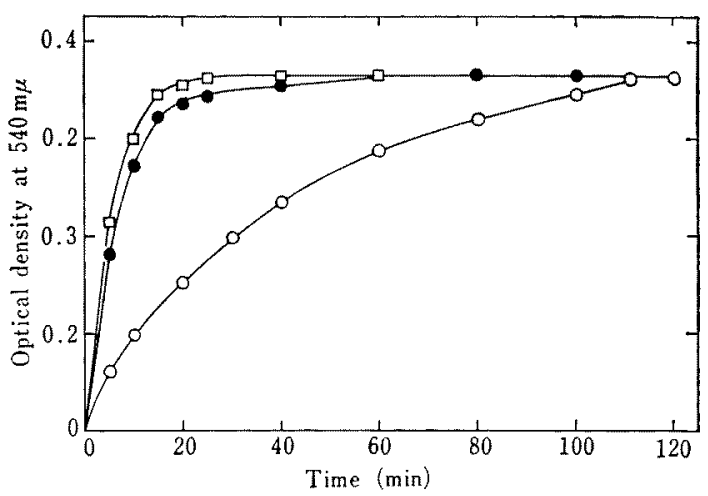

FIG. 2. Rate of Color Development in the Cysteinecarbazole Reaction.

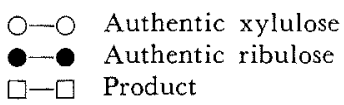

The absorption spectrum in the orcinol reaction and the rate of color development in the cysteine-carbazole reaction ${ }^{12,131}$ of the sirup thus obtained were examined. As shown in Figs. 1 and 2, the results of these tests were similar to those given by an authentic ribulose.

13) F. Dickens and D. H. Williamson, Biochem. J., 64, 567 (1956). 


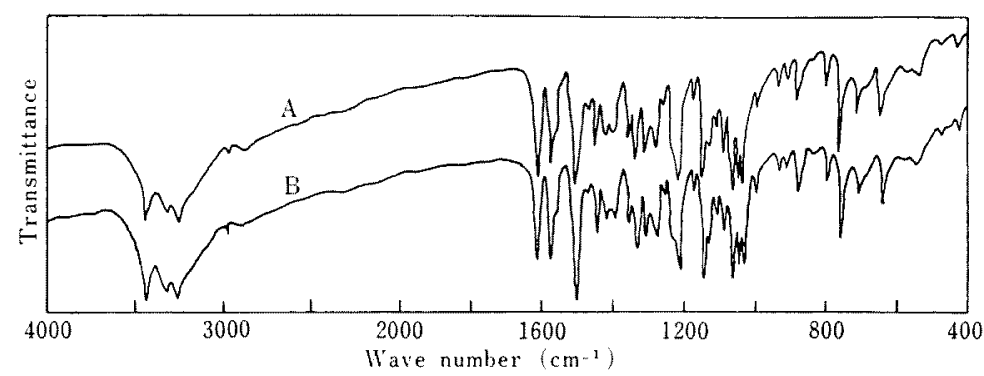

FIG. 3. Infrared Absorption Spectra of o-Nitro-phenylhydrazone of D-Ribulose.
A: Authentic D-ribulose o-nitro-phenylhydrazone.
B: o-Nitro-phenylhydrazone of product.

Further identification of the ketopentose was achieved by the formation of a o-nitro-phenylhydrazone derivative. ${ }^{14}$ The hydrazone was obtained as reddish orange crystals; $\mathrm{mp} 165^{\circ} \mathrm{C}$, $[\alpha]_{\mathrm{D}}^{20}-46.9\left(c=0.32, \mathrm{CH}_{3} \mathrm{OH}\right)$. Anal. Found: $\mathrm{C}, 46.60 ; \mathrm{H}, 5.45 ; \mathrm{N}, 14.83$. Calcd. for $\mathrm{C}_{11} \mathrm{H}_{15} \mathrm{O}_{6} \mathrm{~N}_{3}: \mathrm{C}, 46.32 ; \mathrm{H}, 5.30 ; \mathrm{N}, 14.73 \%$. These characteristics were the same as those of an authentic D-ribulose 0 -nitro-phenylhydrazone. The infrared spectrum of the o-nitrophenylhydrazone of the product was also coincided with that of an authentic specimen (Fig. 3). Therefore, the ketopentose produced by this organism was identified as D-ribulose.

\section{Accumulation of D-ribulose by Corynebacterium sp.} No. 208

\section{1) Effect of thiamine concentration in the medi-} um. Since thiamine was found to be an essential factor for the growth of this organism, the effect of thiamine on the yield of D-ribulose was first investigated. Figure 4 shows the relationship between the thiamine concentration in the medium and the extracellular accumulation of D-ribulose.

As shown in Fig. 4, the maximum accumulation of D-ribulose occurred at the restricted concentration of thiamine for growth and further increase in the thiamine concentration

14) R. M. Hochster, Can. J. Microbiol., 1, 346 (1955).

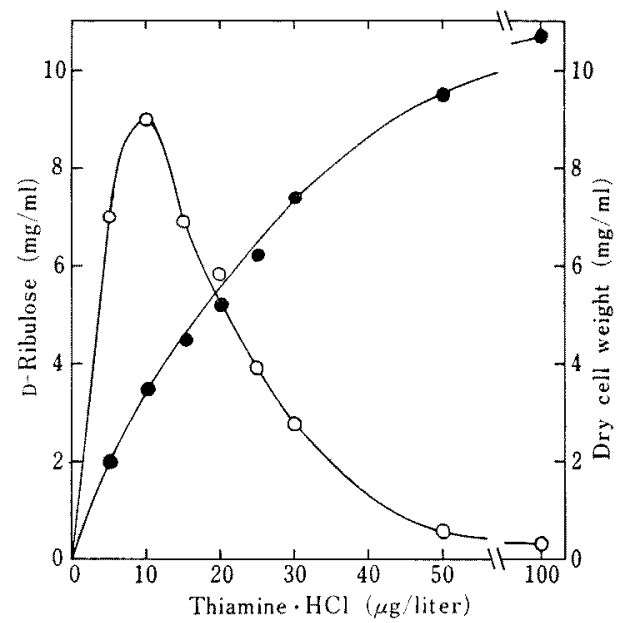

FIG. 4. Effect of Thiamine Concentration on DRibulose Accumulation.

$\begin{array}{ll}\text { O-O } & \text { D-Ribulose } \\ - \text { - } & \text { Dry cell weight }\end{array}$

caused a decrease in the D-ribulose accumulation, though an abundant cell growth was observed. An optimal concentration of thiamine hydrochloride for the accumulation appears to be $10 \mu \mathrm{g}$ per liter. Hence, this concentration was chosen for all subsequent experiments.

2) Effect of nitrogen source concentration. As shown in Fig. 5, an optimal concentration of ammonium sulfate was $0.4 \%$ and higher concentration of ammonium sulfate did not have 
any effect both on the accumulation of Dribulose and on the cell growth.

3) Effect of gluconate concentration. In this experiment, the concentration of thiamine

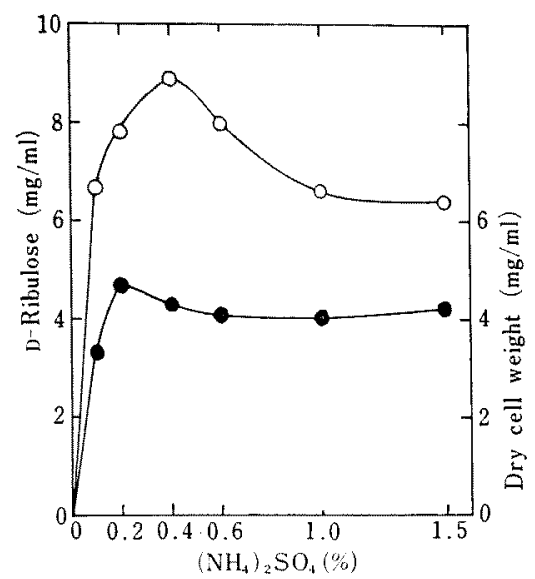

FIG. 5. Effect of Nitrogen Source Concentration on D-Ribulose Accumulation.

\section{O-O D-Ribulose}

Dry cell weight

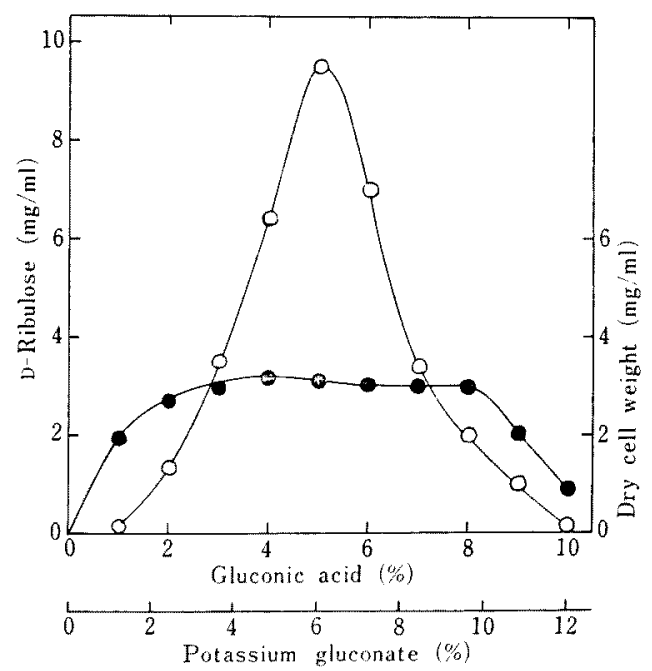

FIG. 6. Effect of Gluconate Concentration on DRibulose Accumulation.

The ratio of gluconic acid to ammonium sulfate was fixed at 12.5 .

O-O D-Ribulose

-D Dry cell weight hydrochloride in the medium was fixed at $10 \mu \mathrm{g}$ per liter and the ratio of gluconic acid to ammonium sulfate was maintained constant at each concentration of gluconic acid. The maximum accumulation of D-ribulose was observed at a gluconic acid concentration of $5 \%$, which was equivalent to a potassium gluconate concentration of $6 \%$, above which the amount of D-ribulose was sharply decreased with further increase in gluconic acid concentration (Fig. 6).

4) Effect of $\mathrm{KH}_{2} \mathrm{PO}_{4}$ and $\mathrm{MgSO}_{4} \cdot 7 \mathrm{H}_{2} \mathrm{O}$. As

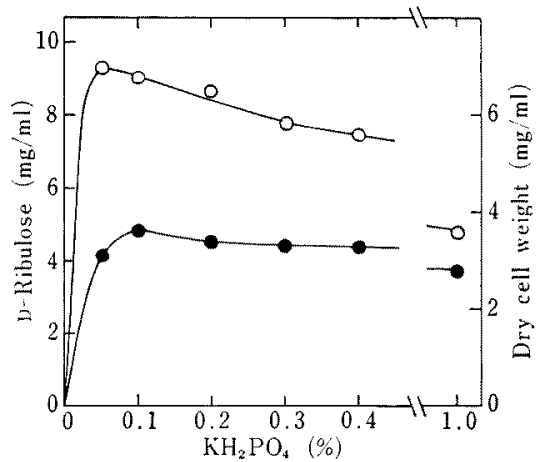

FIG. 7. Effect of $\mathrm{KH}_{2} \mathrm{PO}_{4}$ Concentration on D-Ribulose Accumulation.

O-O D-Ribulose

- Dry cell weight

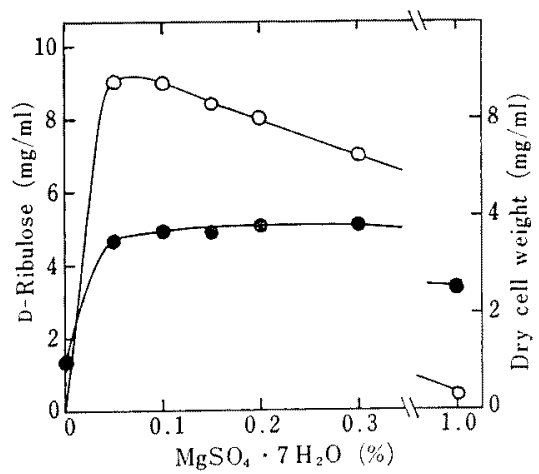

FIG. 8. Effect of $\mathrm{MgSO}_{4} \cdot 7 \mathrm{H}_{2} \mathrm{O}$ Concentration on DRibulose Accumulation.

O-O D-Ribulose

- Dry cell weight 
shown in Figs. 7 and 8, the optimal concentrations of $\mathrm{KH}_{2} \mathrm{PO}_{4}$ and $\mathrm{MgSO}_{4} \cdot 7 \mathrm{H}_{2} \mathrm{O}$ for the accumulation of D-ribulose seemed to lie in the range of $0.05 \sim 0.2 \%$ and $0.05 \sim 0.1 \%$, respectively. On further increasing of the consentration of these salts, the yield of D-ribulose lecreased progressively.

The addition of trace metals such as $\mathrm{Mn}^{2+}$, $\mathrm{Zn}^{2+}, \mathrm{Co}^{2+}, \mathrm{Ni}^{2+}, \mathrm{Fe}^{2+}, \mathrm{Cu}^{2+}, \mathrm{Mo}^{6+}$, and $\mathrm{Sn}^{2+}$ at concentrations lower than $100 \mathrm{ppm}$ also had no marked effect on the D-ribulose aczumulation.

5) Time course of D-ribulose accumulation. The time course of D-ribulose accumulation by this organism in the most favorable medium is presented in Fig. 9. The accumulation of D-ribulose reached the maximum with a yield

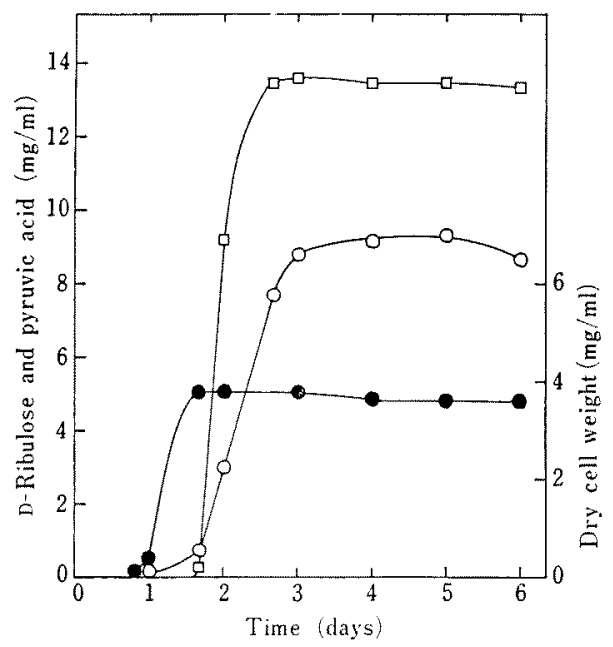

FIG. 9. Time Course of D-Ribulose Accumulation.

The medium consisted of potassium gluconate, $6.0 \% ;\left(\mathrm{NH}_{4}\right)_{2} \mathrm{SO}_{4}, 0.4 \% ; \mathrm{KH}_{2} \mathrm{PO}_{4}, 0.1 \% ; \mathrm{MgSO}_{4}$. $7 \mathrm{H}_{2} \mathrm{O}, 0.05 \%$; and thiamine- $\mathrm{HCl}, 10 \mu \mathrm{g} /$ liter.

Cultivation was carried out at $30^{\circ} \mathrm{C}$ on a reciprocal shaker.

O-O D-Ribulose

$\square-\square$ Pyruvic acid

- Dry cell weight of $9.5 \mathrm{mg}$ per $\mathrm{ml}$ after cessation of the cell growth and the D-ribulose excreted extracellularly was not declined through the period of cultivation.

\section{DISCUSSION}

Although there are some reports regarding the D-ribulose accumulation by microorganisms, the factors influencing the accumulation are not elucidated.

In the present study, D-ribulose accumulation by a thiamine-requiring bacterium, Corynebacterium sp. No. 208, was greatly enhanced when this organism was grown in a thiaminedeficient medium.

The constituents of the medium such as nitrogen source, inorganic salts, and trace metals had no marked effect on the accumulation. It can therefore be presumed that the D-ribulose accumulation is related to the thiamine requirement of this organism and that the accumulation is a consequence of a decrease in the activity of the thiamine-requiring enzymes involved in gluconate catabolism as has been observed for the pyruvic acid accumulation by this organism.

No significant difference between the optimal thiamine concentration for D-ribulose accumulation and that for pyruvic acid accumulation was observed.

As shown in Fig. 6, the optimal concentration of gluconate for the D-ribulose accumulation was $6 \%$ and the increased concentration of gluconate caused a decrease in the accumulation. On the other hand, there was a increase in pyruvic acid accumulation with increasing gluconate concentration up to $10 \%$ as previously reported. From these facts, high concentration of gluconate seems to inhibit the accumulation of D-ribulose and to stimulate that of pyruvic acid in the thiamine-deficient medium. 